\title{
The Use of Polyvinyl Alcohol Glutaraldehyde as Solid-phase in ELISA for Plague
}

\author{
Aureci Maria Araujo/*, André Tavares S Petribú, Gustavo Henrique T Sales \\ Barbosa, José Ricardo P Diniz, Alzira MP de Almeida**, Walter Mendes \\ Azevedo, Elizabeth Malagueño, Luiz B Carvalho Jr/ ${ }^{+}$
}

Laboratório de Imunopatologia Keizo Asami, Universidade Federal de Pernambuco, Cidade Univesitária, 50670420 Recife, PE, Brasil *Fundação de Hematologia e Hemoterapia de Pernambuco, Recife, PE, Brasil **Centro de Pesquisas Aggeu Magalhães - FIOCRUZ, Recife, PE, Brasil

Discs of polyvinyl alcohol cross-linked with glutaraldehyde were synthesized under acid catalysis $\left(\mathrm{H}_{2} \mathrm{SO}_{4}\right)$. Then, the antigen $\mathrm{F} 1$ purified from Yersinia pestis was covalently linked to this modified polymer. Afterwards, an enzyme-linked immunosorbent assay (ELISA) was established for the diagnosis of plague in rabbit and human. The best conditions for the method were achieved by using $1.3 \mu \mathrm{g}$ of F1 prepared in $0.067 \mathrm{M}$ phosphate buffer, $\mathrm{pH} 7.2$, containing $1 \mathrm{M} \mathrm{NaCl}(\mathrm{PBS})$; anti-IgG peroxidase conjugate diluted 6,000 times and as a blocking agent 3\% w/v skim milk in PBS. The titration of positive rabbit serum according to this procedure detected antibody concentrations up to 1:12,800 times. The present method, the conventional ELISA and passive haemagglutination assay are compared.

Key words: polyvinyl alcohol - glutaraldehyde - Yersinia pestis - ELISA - Brazil

Plague, an infection caused by Yersinia pestis, is still a public health problem in many countries in

Africa, Asia and America (Butler 1989). Recently, an outbreak of pneumonic plague occurred in India (WHO 1994). During the period from 1980 to 1993, 736 human cases were registered in Brazil (Vieira et al. 1991). One of our labs (Centro de Pesquisas Aggeu Magalhães - FIOCRUZ) is responsible to monitor the occurrence of plague cases in northeast of Brazil. Therefore, the laboratorial diagnosis is one of the concerned issues being evaluated (Almeida \& Ferreira 1992).

In our laboratories, a dot enzyme linked immunosorbent assay (dot-ELISA) has been previously proposed to detect specific antibodies in rabbits sera immunized against $\mathrm{F} 1$ protein obtained from $Y$. pestis by using a new solid phase - Dacron ${ }^{\circledR}$ (Montenegro et al. 1991, 1993). Furthermore, ferromagnetic Dacron was also suggested as solid phase in enzyme immunodiagnosis (Carneiro Leão et al. 1994).

In this work, another modified polymer, polyvinyl alcohol (PVA) - glutaraldehyde, is investigated as an alternative solid phase to be used in the diagnosis of plague. The advantages of this support are: its easy synthesis; different physical forms

\footnotetext{
This work was supported by FINEP(grant no 66.92.0454.000), CNPq, FACEPE and JICA.

${ }^{+}$Corresponding author. Fax: (081) 271.8485 - E-mail: LBCJ @ NPD1.UFPE.BR

Received 5 July 1995

Accepted 18 December 1995
}

can be achieved (discs, beads, fiber, membrane, etc.); it can be stored; no pre-activation prior protein immobilization is required and its low costs.

\section{MATERIALS AND METHODS}

PVA-glutaraldehyde discs synthesis - PVA $(0.5$ $\mathrm{g}$; Reagen) was dissolved in $5 \mathrm{ml}$ of deionized water by heating under stirring. Then, $1.5 \mathrm{ml}$ of glutaraldehyde (25\%; Reagen) and $1 \mathrm{ml}$ of $0.1 \mathrm{M} \mathrm{H}_{2} \mathrm{SO}_{4}$ (Reagen) were added. Aliquots $(50 \mu \mathrm{l})$ of this mixture were dispensed to "V" bottomed microplates previously siliconized (Sigmacote*) and kept at $25^{\circ} \mathrm{C}$ for the polymerization of the PVA-glutaraldehyde. Around 140 discs were synthesized through this procedure and they were kept in deionized water at $4^{\circ} \mathrm{C}$ until use.

Antigen and sera - Antigen F1 (4 mg/ml) from $Y$. pestis avirulent strain A1122 was obtained according to Baker et al. (1952). Sera from two immunized rabbits against $Y$. pestis $\mathrm{F} 1$ protein were prepared by standard procedures (Bahmanyar \& Cavanaugh 1976). Sera from non-immunized rabbits and $0.067 \mathrm{M}$ phosphate buffer, $\mathrm{pH} 7.2$, containing $1 \mathrm{M} \mathrm{NaCl}$ (PBS) were used as controls. Goat anti-rabbit IgG labeled with horseradish peroxidase was purchased from Sigma Chemical Co. Protein content was established according to Lowry et al. (1951).

Antigen immobilization - The discs were introduced into flat bottomed microplates covered with $100 \mu \mathrm{l}$ of diluted F1 antigen (1.3 $\mu \mathrm{g} /$ well $)$ and left overnight at $4^{\circ} \mathrm{C}$. These treated discs were washed twice with PBS, containing $0.05 \%$ Tween 20 
(Labsynth); blocked with skim milk (3\% w/v in PBS; Molico Milk, Nestle) overnight at $4^{\circ} \mathrm{C}$ and washed with PBS/Tween once.

Enzyme linked immunosorbent assay (ELISA) - Diluted sera (100 $\mu \mathrm{l}$ of a 1:200 and 1:100 dilutions in PBS for rabbit and human, respectively) were incubated with the antigen-disc (F1-disc) into clean microplates at $37^{\circ} \mathrm{C}$ for $1 \mathrm{hr}$. After washing the antibody-antigen-disc complex five times with PBS/Tween, $100 \mu \mathrm{l}$ of either goat anti-rabbit IgG or goat anti-human IgG (Sigma) conjugated to peroxidase diluted 6,000 and 2,500 times, respectively, in $3 \% \mathrm{w} / \mathrm{v}$ skim milk were added and incubated at $37^{\circ} \mathrm{C}$ for $1 \mathrm{hr}$. Afterwards, five washings with PBS/ Tween were carried out. Then, the substrate solution $(100 \mu \mathrm{l})$, composed of $0.325 \% \mathrm{w} / \mathrm{v}$ orthophenylenediamine dihydrochloride (OPDSigma) and $0.085 \% \mathrm{H} 2 \mathrm{O} 2$ prepared in $0.3 \mathrm{M}$ Triscitrate buffer, $\mathrm{pH}$ 6.0, was added and after incubation at room temperature $\left(28^{\circ} \mathrm{C}\right)$ for $15 \mathrm{~min}$, in the dark, the reaction was stopped with $2.5 \mathrm{M} \mathrm{H} 2 \mathrm{SO} 4$ $(25 \mu \mathrm{l})$, the discs removed and the plates read in ELISA reader (Bio-rad) at $492 \mathrm{~nm}$. Conventional ELISA and passive haemagglutination test were performed according to Almeida and Ferreira (1992) and World Health Organization (WHO 1970), respectively.

Optimization of the procedure - The above procedure was standardized according to previous study of the best blocking conditions, titration of conjugate, antigen concentration and titration of tested sera.

Blocking conditions - The blockage of this ELISA was previously established using several concentrations of skim milk, prepared in PBS, at different incubation times. Optical density (OD) values lower than 0.003 for the blank and infrared study of the blocked preparations performed in spectrophotometer Bruker IFS 66 were used as criteria for the best blocking conditions.

Titration of conjugate - Goat anti-rabbit IgG conjugated to horseradish peroxidase was diluted from $1: 1,000$ to $1: 8,000$ in skim milk $3 \% \mathrm{w} / \mathrm{v}$. These dilutions were used to develop the ELISA using $12.5 \mu \mathrm{g}$ of antigen/disc and positive and negative sera diluted 1:6,400. Other experimental conditions were as described above.

Antigen concentration - Samples $(100 \mu \mathrm{l})$ of F1 containing protein at concentrations ranging from 1.3 to $100 \mu \mathrm{g}$ were introduced into flat bottomed microplates and left overnight at $4^{\circ} \mathrm{C}$ so that antigen-discs were synthesized with increasing amount of fixed protein ( $\mathrm{F} 1$ antigen).

Titration of sera - Positive sera were diluted from 1:200 to 1:12,800 in skim milk 3\% w/v and ELISA was carried out following the best condi- tions for blocking conditions, conjugate dilution and antigen concentration.

\section{RESULTS AND DISCUSSION}

The blockage using 3\% w/v skim milk prepared in PBS and incubation overnight at $4^{\circ} \mathrm{C}$ were found to be the best conditions as proved by OD equal to zero for the blanks. Furthermore, infrared spectroscopy of the blocked discs demonstrated that the absorption at wavenumber of $1,723 \mathrm{~cm}^{-1}$, corresponding to the aldehyde carbonyl groups, disappeared after skim milk treatment. Table I shows the relationship between conjugate dilution and the performance of the ELISA. The dilution of 6,000 times can be chosen as an adequate concentration of goat rabbit anti-IgG conjugated to horseradish peroxidase to be used here. It is worthwhile to draw the attention to these results that also show values of OD equal to zero for the negative sera.

The influence of the antigen F1 and antibody (serum) concentrations on the development of ELISA, using PVA-glutaraldehyde as solid-phase, is presented in Fig. 1. Two features can be in-

TABLE I

Determination of optimal conjugate dilution

\begin{tabular}{cccc}
\hline $\begin{array}{l}\text { Conjugate } \\
\text { dilution }\end{array}$ & Blank & Negative & Positive \\
\hline 1,000 & 0 & 0.068 & 0.497 \\
2,000 & 0 & 0.026 & 0.561 \\
3,000 & 0 & 0 & 0.513 \\
4,000 & 0 & 0 & 0.486 \\
5,000 & 0 & 0 & 0.479 \\
6,000 & 0 & 0 & 0.491 \\
7,000 & 0 & 0 & 0.477 \\
8,000 & 0 & 0 & 0.472 \\
\hline
\end{tabular}

The goat rabbit anti-IgG conjugated to horseradish peroxidase was diluted in skim milk $3 \% \mathrm{w} / \mathrm{v}$ and used to develop the ELISA. Positive and negative sera were diluted 6,400 times and other experimental conditions were as described in the text.

ferred: hyperbolic curves are described and their maximum values decrease proportionally to the serum dilution. These can be attributed to the saturation of antigen-antibody complex formation. For instance, a plateau is approximately achieved at antigen concentration higher than $50 \mu \mathrm{g}$ of protein, using serum dilution equal to $1: 12,800$. However, this value decreases whereas the serum dilution decreases. Thus, antigen amount of $1.3 \mu \mathrm{g}$ will be enough for the establishment of ELISA procedure provided that sera dilution higher than 1,600 is used.

The titration of antibodies against $\mathrm{F} 1$ antigen from $Y$. pestis by using PVA-glutaraldehyde as 
solid phase is presented in Fig. 2 which shows that a plateau is obtained at serum dilution higher than 3,200 times, using F1 amount equal to $12.5 \mu \mathrm{g}$ of protein. However, one can conclude from the Fig. 1 that titration of positive serum according to this procedure can detect antibody concentrations up to $1: 12,800$ times.

Therefore, the best conditions for the employment of PVA-glutaraldehyde as solid-phase in ELISA for plague are as follows: antigen F1 amount of $1.3 \mathrm{~g}$ according to Fig. 1; conjugate diluted 6,000 times according to Table I; serum dilution up to 1:12,800 times as shown in Figs 1 and 2 and $3 \% \mathrm{w} / \mathrm{v}$ skim milk in PBS as blocking agent.

This procedure showed to be applicable to detect anti-F1 IgG in human sera collected by the Centro de Pesquisas Aggeu Magalhães from individuals living at different plague foci in northeast of Brazil. The comparison between the present procedure with conventional ELISA and passive haemagglutination assay (PHA) is displayed in Table II. According to this Table one can conclude: a) no correlation between PHA and ELISA results; b) negative results (patient no. 3, 5, 8, 14 and 19) in conventional ELISA were coincident with those in the present method and c) positive results in PHA (patients from no. 23 to 24) were equivalent to high $\mathrm{OD}$ values employing either the conventional or the present ELISA procedures. Almeida and Ferreira (1992) already demonstrated that PHA is not a sensitive test for the diagnosis of plague.

It is worthwhile to observe that the plot of conventional ELISA OD values versus the present

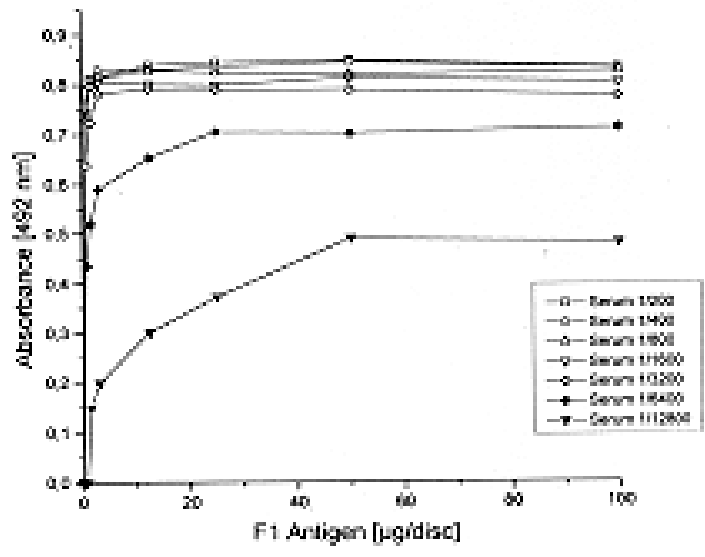

Fig. 1: relationship between F1 antigen and positive serum dilution on the ELISA by using PVA-glutaraldehyde as solid phase. F1 antigen concentration ranged from 1.3 to $100 \mu \mathrm{g}$ of protein per disc and sera containing antibodies against this antigen (positive) were diluted from 1:200 to 1:12,800 in skim milk $3 \% \mathrm{w} / \mathrm{v}$. Other experimental conditions were as described in the text.

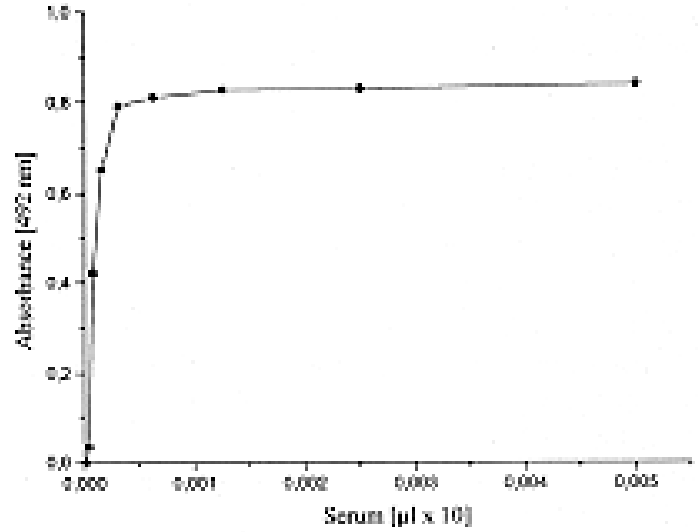

Fig. 2: titration of antibodies against $\mathrm{F} 1$ antigen from Yersinia pestis by using PVA-glutaraldehyde as solid phase in ELISA. Positive sera were diluted from 1:200 to 1:12,800 in skim milk $3 \% \mathrm{w} / \mathrm{v}$ and ELISA was carried out using discs containing $12.5 \mu \mathrm{g}$ of $\mathrm{F} 1$ antigen and other experimental conditions as described.

\section{TABLE II}

Serological analysis of human sera from individuals living at different plague foci in northeast of Brazil

\begin{tabular}{|c|c|c|c|}
\hline \multirow[b]{2}{*}{$\begin{array}{l}\text { Patient } \\
\text { number }\end{array}$} & \multicolumn{3}{|c|}{ Serological assay used } \\
\hline & $\mathrm{PHA}^{a}$ & $\begin{array}{c}\text { ELISA }^{b} \\
\text { conventional }\end{array}$ & $\begin{array}{c}\text { ELISA }^{b} \\
\text { PVA-glutaraldehyde }\end{array}$ \\
\hline 1 & 0 & 0.104 & 0.419 \\
\hline 2 & 0 & 0.209 & 0.574 \\
\hline 3 & 0 & 0.016 & 0 \\
\hline 4 & $1 / 8$ & 0.216 & 0.299 \\
\hline 5 & 0 & 0 & 0 \\
\hline 6 & 0 & 0.089 & 0.320 \\
\hline 7 & 0 & 0.036 & 0.199 \\
\hline 8 & 0 & 0 & 0 \\
\hline 9 & 0 & 0.184 & 0.464 \\
\hline 10 & $1 / 16$ & 0.236 & 0.357 \\
\hline 11 & 0 & 0.215 & 0.372 \\
\hline 12 & 0 & 0.076 & 0.278 \\
\hline 13 & 0 & 0.203 & 0.418 \\
\hline 14 & $1 / 8$ & 0.026 & 0 \\
\hline 15 & $1 / 8$ & 0.292 & 0.469 \\
\hline 16 & 0 & 0.073 & 0.227 \\
\hline 17 & 0 & 0.223 & 0.369 \\
\hline 18 & $1 / 8$ & 0.117 & 0.328 \\
\hline 19 & 0 & 0 & 0 \\
\hline 20 & 0 & 0.327 & 0.743 \\
\hline 21 & 0 & 0.116 & 0.244 \\
\hline 22 & $>1 / 128$ & 0.748 & 1.817 \\
\hline 23 & $>1 / 128$ & 0.566 & 1.346 \\
\hline 24 & $>1 / 64$ & 0.223 & 0.722 \\
\hline cut-off & - & 0.058 & 0.276 \\
\hline
\end{tabular}

$a$ : passive haemagglutination assay in reciprocal antibody titres

$b$ : optical densities at $492 \mathrm{~nm}$ 
ELISA yielded a linear relationship ( $\mathrm{R} \pm$ s.d. equal to $0.96256 \pm 0.04936$ ) according to the equation:

$\mathrm{OD}_{\text {conventional ELISA }}=0.010+\mathrm{OD}_{\text {PVA-glutaraldehyde ELISA }}$ x 0,406

The laboratorial diagnosis of plague is still an important issue in public health. Almeida and Ferreira (1992) have suggested dot enzymeimmunosorbent assay (DOT-ELISA) as the more sensitive, easier and faster procedure. However, this method depends on subjective interpretation (visualization of the spots). Recently, Cao et al. (1995) have described the detection of $Y$. pestis F1 antigen by using a fiber optic biosensor but it is still a sophisticated procedure to be employed in developing countries. Therefore, ELISA remains the most reliable method.

The results of the present procedure indicate that a covalent immobilization of $Y$. pestis $\mathrm{F} 1$ antigen on an alternative solid-phase (PVA/glutaraldehyde) was achieved which can be applied for the diagnosis of plague (ELISA). The low prices of the employed reagents are also economically attractive and other physical shapes of PVA-glutaraldehyde (beads, membranes, fiber, etc.) can be used for immunoabsorbent purpose. For instance, investigations on the use of PVA-glutaraldehyde to cover surfaces are in progress. Furthermore, attempts to change the incubation and washing conditions of the described steps in this work are in progress in order to make the time of the procedure shorther.

\section{REFERENCES}

Almeida AMP, Ferreira LCS 1992. Evaluation of three serological tests for the detection of human plague in Northeast Brazil. Mem Inst Oswaldo Cruz, 87: 8792.

Bahmanyar M, Cavanaugh DC 1976. Plague manual. World Health Organization, Geneve, 77 pp.

Baker EE, Sommer H, Foster LE, Meyer E, Meyer KF 1952. Studies on immunization against plague. I. The isolation and characterization of the soluble antigen of Pasteurella pestis. J Immunol 68: 131-140.

Butler T 1989. The black death past and present. 1. Plague in the 1980s. Trans $R$ Soc Trop Med Hyg 83: 458-460.

Cao LK, Anderson GP, Ligler FS, Ezzell J 1995. Detection of Yersinia pestis Fraction 1 antigen with a fiber optic biosensor. J Clin Microbiol 33: 336-341.

Carneiro Leão AMA, Carvalho Jr LB, Malagueño E 1994. The use of ferromagnetic dacron as solid-phase in enzyme immunoassays. Mem Inst Oswaldo Cruz. 89: 189-193.

Lowry OH, Rosenrough NJ, Farr AL, Randall RJ 1951. Protein measurement with the folin phenol reagent. J Biol Chem 193: 265-275.

Montenegro SML, De Almeida AMP, Carvalho AB, Carvalho Jr LB 1991. The use of dacron plates for dot enzyme-linked immunosorbent assay (dotElisa). Mem Inst Oswaldo Cruz 86: 461-465.

Montenegro SML, Almeida AMP, Carvalho Jr LB 1993. Standardization of the dot enzyme-linked immunosorbent assay (dot-ELISA) for experimental plague. Mem Inst Oswaldo Cruz. 88: 119-123.

Vieira JBF, Almeida AMP, Almeida CR 1991. Epidemiologia e controle da peste no Brasil. Rev Soc Bras Med Trop 27(Suppl III): 51-58.

WHO - World Health Organization 1970. Technical Report Series. WHO Expert Committee on Plague, Forth Report. Bull Wrld Hlth Org 42: 993-997.

WHO - World Health Organization 199sw4. Weekly epidemiological record, no. 42, p.316. 